\title{
Potensi Sari Pati Gadung (Dioscorea hispida L.) Sebagai Bioinsektisida Hama Walang Sangit Pada Tanaman Padi (Oryza sativa $\mathbf{L}$.)
}

\author{
ZICO FAKHRUR ROZI ${ }^{1}$, YULI FEBRIANTI ${ }^{1}$, YARDIANI TELAUMBANUA $^{1}$ \\ ${ }^{1}$ Program Studi Pendidikan Biologi STKIP PGRI Lubuklinggau \\ Jl. Mayor Toha Kelurahan Air Kuti, Lubuklinggau Timur I, Lubuklinggau, \\ Sumatera Selatan. 31626 \\ Email: zico.fakhrurrozi@gmail.com
}

Received 24 January 2018; Received in revised form 1 February 2018;

Accepted 11 February 2018; Available online 25 March 2018

\begin{abstract}
Walang sangit (Leptocorisa acuta L.) as a rice bug is a pest that can cause a decrease in rice production (Oryza sativa L.). Excessive use of chemical pesticides will cause resistance or immunity to the pest itself. Gadung (Dioscorea hispida L.) has a compound HCN (cyanide acid) that potentially cause metabolic disturbance in insects. This study aims to determine the extract of gadung tuber effect as bioinsecticide of rice bug against rice. This research was conducted in Biology Laboratory of STKIP PGRI Lubuklinggau South Sumatera Province, with 5 treatment groups and 5 replications. The research design used was complete randomized design (RAL) with P0 control (-) without giving of starch bulb, P1 $20 \mathrm{gr} / 1, \mathrm{P} 240 \mathrm{gr} / 1, \mathrm{P} 360 \mathrm{gr} /$ 1, P4 $80 \mathrm{gr} / 1$. Based on the results of analysis with Anava One Path test obtained results $\mathrm{F}_{\text {count }}=7.72$ with $\mathrm{F}_{\text {table }}=4.43$. It shows there is a significant influence of the extract of gadung tuber as bioinsecticide of rice bug against rice plant.
\end{abstract}

Keywords: bioinsecticide, Dioscorea hispida L., Leptocorisa acuta L., Oryza sativa L.

\section{INTISARI}

Walang sangit (Leptocorisa acuta L.) merupakan hama yang dapat menyebabkan penurunan produksi tanaman padi (Oryza sativa L.). Penggunaan pestisida kimia yang berlebihan akan menyebabkan resistensi atau kekebalan pada hama itu sendiri. Tanaman gadung (Dioscorea hispida L.) memiliki senyawa HCN (asam sianida) yang berpotensi menimbulkan gangguan metabolisme pada serangga. Penelitian ini bertujuan mengetahui pengaruh sari pati umbi gadung sebagai bioinsektisida hama walang sangit pada tanaman padi. Penelitian ini dilaksanakan di Laboratorium Biologi STKIP PGRI Lubuklinggau Provinsi Sumatera Selatan, dengan 5 kelompok perlakuan dan 5 ulangan. Rancangan penelitian yang digunakan adalah rancangan acak lengkap (RAL) dengan P0 kontrol (-) tanpa pemberian sari pati umbi gadung, P1 20 gr/l, P2 40 gr/l, P3 60 gr/l, P4 80 gr/l. Berdasarkan hasil analisis dengan uji Anava Satu Jalur diperoleh hasil $F_{\text {hitung }}=7,72$ dengan $F_{\text {tabel }}=$ 4,43, sehingga menunjukkan ada pengaruh signifikan sari pati umbi gadung sebagai bioinsektisida hama walang sangit pada tanaman padi.

Kata kunci: bioinsektisida, Dioscorea hispida L., Leptocorisa acuta L., Oryza sativa L.

\section{PENDAHULUAN}

Tanaman padi merupakan tanaman budidaya yang sangat penting bagi manusia karena lebih dari setengah penduduk Indonesia tergantung pada tanaman ini sebagai sumber bahan pangan (Pracaya dan Kahono, 2011). Hama Walang sangit (Leptocorisa acuta L.) merupakan salah satu faktor yang menyebabkan produksi tanaman padi menurun. Walang sangit merupakan hama perusak buah yang menyebabkan buah menjadi kosong (Tiwari et al., 2011). Walang sangit juga menyerang buah padi dalam kondisi masak susu, mengisap cairan dalam buah padi sehingga menyebabkan buah padi tersebut menjadi kosong (Pracaya dan Kahono, 
2011). Kerusakan padi akibat serangan Leptocorisa dilaporkan dapat mencapai $98.7 \%$ (Bhadauria and Singh, 2009).

Penggunaan pestisida oleh petani berdampak negatif pada beberapa aspek, seperti lahan pertanian, perikanan, flora dan fauna, bahkan meningkatkan mortalitas manusia yang terpapar oleh pestisida tersebut (Wilson and Tisdell, 2001). Penggunaan yang berlebihan menyebabkan resistensi terhadap hama itu sendiri. Salah satu alternatif dalam pengendalian penggunaan hama adalah penggunaan biopestisida, yang bertujuan untuk mengurangi kepadatan populasi (Aziz, 2014). Mengingat hal tersebut maka pilihan yang baik saat ini adalah dengan menggunakan bioinsektisida.

Bioinsektisida merupakan jenis pestisida yang terbuat dari bahan alami atau makhluk hidup untuk mengontrol hama tanaman, seperti serangga (Chandler et al., 2011). Salah satu tumbuhan yang digunakan sebagai bahan bioinsektisida adalah gadung (Discorea hispida L.). Gadung mengandung racun berupa senyawa $\mathrm{HCN}$ (asam sianida), dioscorin dan histamin yang berpotensi menimbulkan gangguan metabolisme, gangguan syaraf, hingga menyebabkan kematian (Bhandari and Kawabata, 2005).
Dilaporkan Saleha $d k k$ (2018), kandungan sianida tertinggi dalam umbi-umbian mencapai 739 ppm. Berdasarkan uraian tersebut maka perlu dilakukan penelitian secara ilmiah untuk mengetahui potensi sari pati gadung sebagai bioinsektisida hama walang sangit tanaman padi.

\section{METODE}

Penelitian ini dilaksanakan di Laboratorium Biologi STKIP PGRI Lubuklinggau Provinsi Sumatera Selatan.

Rancangan Percobaan. Penelitian ini menggunakan Rancangan Acak Lengkap (RAL) dengan 5 kelompok perlakuan dan 5 ulangan. P0 kontrol (-) tanpa umbi gadung, P1 $20 \mathrm{gr} / \mathrm{l}$, P2 $40 \mathrm{gr} / \mathrm{l}$, P3 $60 \mathrm{gr} / \mathrm{l}$, P4 80 gr/l) dengan 5 pengulangan. Perlakuan hewan uji berdasarkan rumus Federer: $(\mathrm{t}-1)(\mathrm{r}-1) \geq 15$, (t) merupakan jumlah perlakuan untuk setiap kelompok perlakuan dan (r) adalah jumlah ulangan (Hanafiah, 2016). Konsentrasi bioinsektisida umbi gadung yang digunakan pada penelitian ini adalah hasil modifikasi penelitian Butarbutar dkk., (2013) dan berdasarkan uji pendahuluan yang telah dilakukan. Rancangan percobaan pengaruh sari pati gadung sebagai bioinsektisida hama walang sangit tanaman padi tabel 1 .

Tabel 1. Rancangan Penelitian

\begin{tabular}{ccc}
\hline Perlakuan & Ulangan & Konsentrasi Sari Pati Gadung (gr/l) \\
\hline P0 & 5 & $0 \mathrm{gr} / \mathrm{l}$ \\
\hline P1 & 5 & $20 \mathrm{gr} / \mathrm{l}$ \\
P2 & 5 & $40 \mathrm{gr} / 1$ \\
\hline P3 & 5 & $60 \mathrm{gr} / 1$ \\
\hline P4 & 5 & $80 \mathrm{gr} / 1$ \\
\hline
\end{tabular}

Pembuatan Bioinsektisida. Umbi gadung diperoleh dari hutan sekitar kelurahan talang rejo, Kec. Lubuklinggau barat II Provinsi Sumatera Selatan. Umbi gadung yang telah dipilih, dikupas, dicuci dan diblender. Sebelum diblender umbi gadung yang telah dipilih ditimbang berdasarkan konsentrasi yang dibutuhkan.

Misalnya pada P1, konsentrasi yang dibutuhkan yaitu 20 gram umbi gadung kemudian dimasukkan ke dalam blender dan ditambahkan akuades 1 liter. Cara ini dilakukan pada pembuatan bioinsektisida P2 (40 gram), P3 (60 gram), dan P4 (80 gram) (Setiawati, 2008).

Penyemprotan Bioinsektisida. Walang sangit diperoleh dengan membeli kepada petani sawah. Walang sangit yang digunakan dalam penelitian ini adalah walang sangit yang dewasa panjang 16-18 mm. Walang sangit yang telah disediakan, dimasukkan dalam toples tempat perlakuan. Setiap toples masingmasing berisi 10 ekor walang sangit dan diberikan perlakuan dengan konsentrasi yang 
berbeda-beda sesuai perlakuan, yakni 3 kali semprotan untuk setiap toples perlakuan. Pada P0 (kontrol) disemprotkan dengan akuades. Perlakuan P1 walang sangit disemprot dengan bioinsektisida sari pati gadung dengan konsentrasi $20 \mathrm{gr} / \mathrm{l}$ akuades. Perlakuan P2 walang sangit disemprotkan dengan bioinsektisida sari pati gadung dengan konsentrasi $40 \mathrm{gr} / \mathrm{l}$ akuades. Perlakuan P3 walang sangit disemprotkan dengan bioinsektisida sari pati gadung dengan konsentrasi 60 gr/l akuades. Perlakuan P4 walang sangit disemprotkan dengan bioinsektisida sari pati gadung $80 \mathrm{gr} / \mathrm{l}$ akuades. Setelah penyemprotan selesai, tahap selanjutnya adalah tahap pengamatan dan pengambilan data.

Analisis Data. Pengumpulan data dilakukan secara observasi selama 24 jam setelah perlakuan. Data yang diperoleh diambil dengan menggunakan lembar pengamatan. Pengambilan data jumlah walang sangit yang mati dilakukan pada akhir penelitian yakni dengan menghitung jumlah walang sangit yang mati pada setiap perlakuan. Data mortalitas walang sangit yang diperoleh diuji dengan perhitungan uji Normalitas, perhitungan uji Homogen, perhitungan uji Analisis Varian (ANAVA) satu jalur dan uji lanjutan dengan Beda Nyata Jujur (BNJ).

\section{HASIL}

Hasil analisis data antar perlakuan terlihat bahwa semakin tinggi konsentrasi dosis bioinsektisida yang diberikan maka semakin tinggi mortalitas walang sangit. Data mortalitas walang sangit disajikan pada tabel 2.

Tabel 2. Data Mortalitas Walang Sangit

\begin{tabular}{ccccccc}
\hline $\mathbf{P}$ & & Jumlah Walang Sangit Yang Mati Ulangan ke- & \multirow{2}{*}{ Rata-Rata $^{ \pm \text {SD }}$} \\
\cline { 2 - 6 } & $\mathbf{1}$ & $\mathbf{2}$ & $\mathbf{3}$ & $\mathbf{4}$ & $\mathbf{5}$ & \\
\hline P0 & 2 & 0 & 2 & 2 & 0 & $1,2^{ \pm 86,8 \mathrm{a}}$ \\
\hline P1 & 4 & 5 & 5 & 3 & 3 & $4^{ \pm 86,8 \mathrm{a}}$ \\
\hline P2 & 10 & 6 & 6 & 2 & 3 & $5,4^{ \pm 86,8 \mathrm{~b}}$ \\
\hline P3 & 5 & 6 & 10 & 5 & 4 & $6^{ \pm 86,8 \mathrm{~b}}$ \\
\hline P4 & 6 & 9 & 10 & 10 & 6 & $8,2^{ \pm 86,8 \mathrm{~b}}$ \\
\hline
\end{tabular}

\begin{tabular}{ll}
\hline Keterangan: & \\
P0(-) & : akuades \\
P1(20 gram) & $:$ 20 gram umbi gadung +1 liter akuades \\
P2(40 gram) & $:$ 40 gram umbi gadung +1 liter akuades \\
P3(60 gram) & $:$ 60 gram umbi gadung +1 liter akuades \\
P4(80 gram) & $:$ : 0 gram umbi gadung +1 liter akuades \\
a & : tidak berbeda nyata $(5 \%)$ \\
b & : tidak berbeda nyata $(5 \%)$
\end{tabular}

Berdasarkan hasil uji potensi sari pati gadung sebagai bioinsektisida hama walang sangit tanaman padi yang telah dilakukan dengan konsentrasi P0 (akuades), P1 (20 gr/l), P2 (40 gr/l), P3 (60 gr/l), dan P4 (80 gr/l) menunjukkan hasil yang sangat signifikan. Hal ini terlihat pada perhitungan Anava Satu Jalur didapat $F_{\text {hitung }}=7.72>F_{\text {tabel }}=4,43$. Maka dapat dinyatakan bahwa nilai $\mathrm{F}_{\text {hitung }}>\mathrm{F}_{\text {tabel }}$ maka $\mathrm{H}_{0}$ ditolak dan $\mathrm{H}_{1}$ diterima dan dapat disimpulkan ada pengaruh sari pati gadung sebagai bioinsektisida hama walang sangit tanaman padi.

Selanjutnya dilakukan perhitungan Koefisien Keragaman (KK). Pada perhitungan
KK diperoleh KK sebesar 0,08\%. Hal ini menunjukkan bahwa uji lanjutan yang sebaiknya digunakan adalah uji Beda Nyata Jujur (BNJ) (Hanafiah 2016). Pada perhitungan statistik Uji Beda Nyata Jujur (BNJ) diperoleh $\mathrm{P} 2$ dengan konsentrasi $40 \mathrm{gr} / 1$ telah optimum dalam membunuh walang sangit sebanyak 27 ekor karena dengan konsentrasi $40 \mathrm{gr} / 1$ tersebut berbeda nyata dengan P1 (20 gr/l) yang membunuh walang sangit sebanyak 20 ekor. Perlakuan P4 paling banyak membunuh walang sangit dengan jumlah 41 ekor, dosis yang diberikan pada perlakuan P4 $80 \mathrm{gr} / 1$, hal ini dikarenakan racun yang terdapat di dalam sari pati gadung berupa 
asam sianida dan dioscorin merupakan racun penyebab kejang.

\section{PEMBAHASAN}

Pada penelitian ini, umbi gadung yang digunakan adalah umbi tua. Hal tersebut didasarkan pada penelitian Mutiara dan Novalia (2010), bahwa semakin tua umur umbi gadung, maka kadar racun yang dikandungnya akan semakin pekat dan berwarna hijau. Umbi dalam fase ini dapat menyebabkan keracunan, bahkan kematian. Sehingga relevan dijadikan sebagai bahan bioinsektisida.

Kematian walang sangit diduga akibat senyawa racun yang dimiliki oleh gadung. Proses masuknya racun ke dalam tubuh walang sangit melalui saluran pernapasan dan organ pencernaan walang sangit, terserap oleh dinding-dinding alat pencernaan tersebut, kemudian menyebar hingga ke pusat saraf sehingga akan berpontensi memberikan tekanan serta menurunkan metabolisme organ dalam dan menghambat aktivitas metabolisme walang sangit sehingga mengalami kematian (Afifah $d k k$., 2015). Hal ini diperjelas oleh Djaafar dkk. (2009), umbi gadung mengandung senyawa glukosida saponin yang termasuk alkaloid tropan yang disebut dioscorin dan senyawa glukosida sianogenik yang jika terurai menghasilkan asam sianida. Dua senyawa tersebut memiliki toksisitas tinggi yang dapat mengganggu sistem saraf bagi yang mengkonsumsi.

Walang sangit yang mati ditandai dengan pergerakan kaki yang tidak aktif, tubuh lemas dan warnanya berubah kecokelatan. Setelah diamati selama kurang lebih dua menit, apabila walang sangit tidak bergerak maka dinyatakan mati. Pada perlakuan dengan konsentrasi 80 gr/l walang sangit paling banyak mengalami kematian dengan jumlah 41 ekor. Meskipun demikian cara kerja bioinsektisida relatif lebih lama. Kendala tersebut dapat diminimalisir dengan mengutamakan teknik pemberian bioinsektisida yang benar, waktu pemberian bioinsektisida yang tepat takaran dan sasaran.

\section{KESIMPULAN}

Berdasarkan hasil analisis data mortalitas walang sangit dengan menggunakan Uji
Anava dapat ditarik kesimpulan bahwa sari pati gadung berpengaruh sebagai bioinsektisida hama walang sangit pada tanaman padi.

\section{DAFTAR PUSTAKA}

Afifah F, Rahayu YS, Faizah U. 2015. Efektivitas Kombinasi Filtrat Daun Tembakau (Nicotiana tabacum) dan Filtrat Daun Paitan (Thitonia diversifolia) sebagai Pestisida Nabati Hama Walang Sangit (Leptocorisa oratorius) pada Tanaman Padi. Lentera Bio. vol 4(1): 25 31.

Aziz IR. 2014. Kemampuan Tumbuh Pseudomonas Putida Strain 071 Pada Medium Diazinon. Jurnal Teknosains. vol 8(1): 87-94.

Bhadauria NS and Singh P. 2009. Assessment of Losses in Paddy Caused Leptocorisa varicornis. Annals of Plant Protection Sciences. vol 17(1): 231.

Bhandari MR and Kawabata J. 2005. Bitterness and Toxicity in Wild Yam (Dioscorea spp.) Tubers of Nepal. Plant Foods for Human Nutrition. vol 60: 129135. https://doi.org/10.1007/s11130-0056841-1.

Butarbutar R, Tobing MC, Tarigan MU. 2013. Pengaruh Beberapa Jenis Pestisida Nabati Untuk Mengendalikan Ulat Grayak Spodoptera litura F. (Lepidoptera: Noctuidae) Pada Tanaman Tembakau Deli di Lapangan. Jurnal Online Agroekoteknologi. vol 1(4): 1484-1494.

Chandler D, Bailey AS, Tatchell GM, Davidson G, Greaves J, Grant WP. 2011. The Development, Regulation and Use of Biopesticides for Integrated Pest Management. Phil. Trans. R. Soc. B. vol 366: 1987-1998. https://doi.org/10.1098/rstb.2010.0390

Djaafar Tf, Rahayu S, Gardjito M. 2009. Pengaruh Blanching dan Waktu Perendaman Dalam Larutan Kapur Terhadap Kandungan Racun Pada Umbi dan Ceriping Gadung. Penelitian 
Pertanian Tanaman Pangan. vol 28(3): 192-198.

Hanafiah KA. 2016. Rancangan Percobaan Teori dan Aplikasi. Jakarta: PT Raja Grafindo Persada.

Mutiara D dan Novalia N. 2010. Uji Toksisitas Akut Ekstrak Umbi Gadung (Dioscorea hispida Dennst) Terhadap Kematian Larva Spodoptera litura F. Sainmatika. vol 7(2): 26-32.

Pracaya dan Kahono PC. 2011. Kiat Sukses Budidaya Padi. Singkawang: PT. Macanan Jaya Cemerlang.

Saleha S, Saidi N, Saiful, Murniana, Rasnovi S, Iqbalsyah TM. 2018. Nutritional Composition of Dioscorea hispida from Different Locations around Leuser Ecosystem Area. Jurnal Natural. vol
18(1):

$1-6$. https://doi.org/10.24815/jn.v18i1.8504.

Setiawati W. 2008. Tumbuhan Bahan Pestisida Nabati dan Cara Pembuatannya Untuk Mengendalikan Organisme Pengganggu Tanaman (OPT). Bandung: Balai Penelitian Tanaman Sayuran.

Tiwari GN, Prasad CS, Nath L. 2011. Arthropod Diversity in Brinjal Ecosystem and its Relation with Weather Factors in Western Uttar Pradesh. Trends in Biosciences. vol 4(1): 12-18.

Wilson C and Tisdell C. 2001. Why Farmers Continue to Use Pesticides Despite Environmental, Health and Sustainability costs. Ecological Economics. vol 39(3): 449-462. https://doi.org/10.1016/S09218009(01)00238-5. 